\title{
The effect of pulverization methods on the microstructure of stiff, ductile, and flexible carbon aerogels
}

\author{
Marina Schwan ${ }^{1, *}$ (1) Jessica Schettler ${ }^{1}$, Felix M. Badaczewski ${ }^{2}$, Charlotte Heinrich $^{1}$, \\ Bernd M. Smarsly ${ }^{2}$, and Barbara Milow ${ }^{1}$ \\ ${ }^{1}$ Institute of Materials Research, German Aerospace Center, Linder Höhe, 51147 Cologne, Germany \\ ${ }^{2}$ Institute of Physical Chemistry, Justus-Liebig-University Giessen, 35392 Giessen, Germany
}

Received: 12 November 2019

Accepted: 25 January 2020

Published online:

10 February 2020

(C) The Author(s) 2020

\begin{abstract}
Carbon aerogels find application in many fields. In most of the applications, they are used as powders and thus need to be pulverized. However, the pulverization could induce various changes in the microstructure of carbon aerogels. The extent of changes depends not only on the dominant forces of used technique, but also on the mechanical and structural properties of initial monolithic samples. In the present work, we discuss the influence of grinding, milling in shaker cryo-mill, and planetary ball mill on stiff, ductile and flexible carbon aerogels. Scanning electron microscopy and transmission electron microscopy images, gas sorption techniques, wide-angle $\mathrm{X}$-ray scattering, and Raman spectroscopy show a strong dependency of the introduced energy amount while pulverization on the structure modification. Results show that stiff carbon aerogels do not undergo noticeable changes. In contrast, ductile carbon aerogels are very sensitive to friction forces. Soft and flexible carbon aerogels undergo drastic changes in the microstructure.
\end{abstract}

\section{Introduction}

Carbon aerogels are well-known open porous solid materials, first introduced by Richard Pekala in 1989 [1]. Usually, carbon aerogels are derived by means of the pyrolysis of organic precursors such as resorcinol-formaldehyde, melamine-formaldehyde [2], phenolic-furfural mixture [3], and other organic precursors. Due to their high inner surface area up to 2000-2500 $\mathrm{m}^{2} \mathrm{~g}^{-1}$, high pore volume of about
3-5 $\mathrm{cm}^{3} \mathrm{~g}^{-1}$ [4], carbon aerogels have a broad application field. Their field of electrical application extends from supercapacitors [5] to rechargeable lithium-based batteries [6]. Metal-doped carbon aerogels could be used as a catalyst material [7]. Carbon aerogels also were successfully used in foundry applications, for the adsorption of foundry gases [8].

Mostly carbon aerogels are pulverized prior to their application. To produce carbon aerogels in a

Address correspondence to E-mail: marina.schwan@dlr.de 
powdered form, the monolithic sample can easily be grinded manually using sand paper (Fig. 1). The accruing powder is then collected from the surface and can be used for any application. On the one side, the grinding method is fast, cheap and demands no energy costs. On the other side, it is difficult to reproduce the powder quality because the hand pressure on the sample and also the velocity of grinding, vary very strongly from person to person. Nevertheless, during grinding, only low forces are applied to the sample which makes the method applicable for fragile or soft materials.

Among the many milling techniques, shaker milling is based on frequent percussions of a steel or ceramic bar or balls inside of the milling container. Figure 1 shows schematically the setup of the mill. Prior to milling, the container will be filled with the sample and fixed on the sides. Depending on frequency, the steel bar will oscillate in the container and through the powerful impacts, crush the sample. The shaker mills are often used under cryo temperatures, whereby the container is arranged in liquid nitrogen. The use of cryo-mill leads to embrittlement of material and is especially applicable for soft and heat-sensitive materials.

Milling in a planetary ball mill is the most frequently used method to get carbon aerogel powder, where the monolithic aerogel is placed in a container with balls made of, e.g., ceramic or steel $[9,10]$. The container of the planetary ball mill mechanically rotates on its axis and powders the material to fine powder through the pressure, friction, cutting, centrifugal, and shearing forces between balls, container walls and samples. The supporting disk rotates in the opposite direction leading to moving of the ball mills in a complex manner. The schematic of functionality is shown in Fig. 1. The energy input changes in material and in turn the homogeneity of resulted powder depends on the milling duration, number of balls inside of the milling beaker, and the number of milling repetitions. The longer the milling time, the higher is the energy amount and the higher the changes in microstructure. Additionally, the ratio between sample volume and ball volume in the container plays an important role. For obtaining very fine powder, a high volume of balls and a low amount of sample were used. Due to high frictional forces between the balls and the sample, severe damage in the microstructure could be expected for soft materials.

The mechanical energy in a planetary ball mill can not only cause the fragmentation of materials but also can induce a chemical reaction between the solid reagents. Immohr et al. reported the catalytic CO oxidation under in situ ball milling conditions where the reaction rate was increased by three orders of magnitude [11]. The influence of mechanical forces on the chemical reactivity of molecules (bond breaking and formation of new bonds) was studied by Craig [12]. These works indicate clearly very highenergy input by using of planetary ball mill.

The usage of mortar to obtain pulverized carbon aerogel has also been investigated [13]. The research group of Leventis introduced laser micromachining method to cut aerogel monoliths into small pieces [14]. They studied the cut aerogel surface and came to a conclusion that the mechanical stresses generated during cutting changes the morphology of the aerogels. Recently, Zanini et al. investigated the

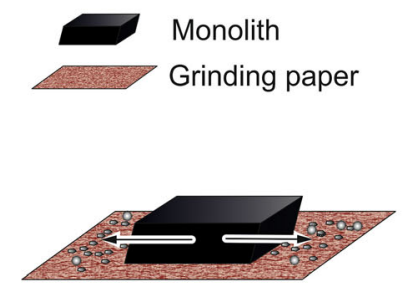

Grinding
Do Aerogel powder

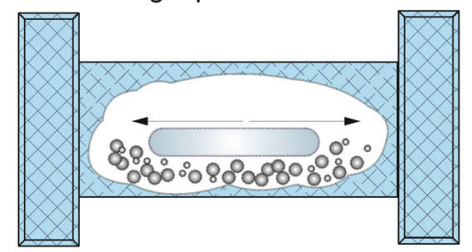

Shaker mill

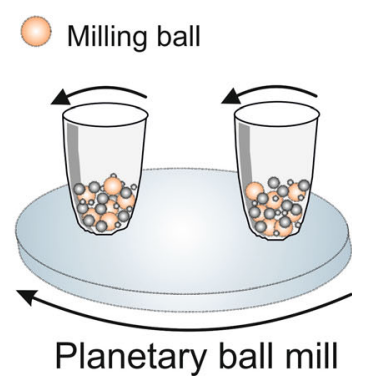

Figure 1 Different techniques for pulverization. Grinding is a low-energy method, especially applicable to fragile materials. In the shaker cryo-mill, the material is crashed through powerful, frequent impacts. The milling in planetary ball mill is based on pressure, cutting, shearing, and friction forces between balls and material. The most of milling processes apply high energy amount on sample and can destroy the structure of material. 
pulverization of cellulose aerogels by means of mechanical grinding [15].

In this work, three different milling methods are compared and the effect of each method on the microstructure of carbon aerogel powders is studied. By means of microscopy, gas sorption techniques, X-ray diffraction, and Raman spectroscopy, the alterations in the microstructure of aerogels were investigated. The grinding based on low pressure and friction forces was used as a simple pulverization method with the lowest energy input. Due to its moderate frequency vibration at low temperature, the shaker cryo-mill was identified as a low-energy method. Lastly, the planetary ball mill was marked as an energy intensive process and was denoted as highenergy technique.

Additionally, for the comparison of the results obtained by means of different techniques, carbon aerogels having different mechanical properties ranging from flexible to stiff were used. This study shows a strong dependency between the main principles of the milling process and the mechanical properties of aerogels.

\section{Materials and methods}

\section{Classification of aerogels}

For our study, we produced three types of resorcinolformaldehyde (RF) aerogels and carbonized them to carbon aerogels (CA). The first type is termed $\mathrm{p}-\mathrm{RF}$ aerogel (based on the work of Richard Pekala) and its carbonized form ductile carbon aerogel ( $\mathrm{p}-\mathrm{CA}$ ). A second type, stiff RF aerogel (s-RF) [16], resulted in carbonized stiff carbon aerogel (s-CA). The third type is a flexible RF aerogel (f-RF), and its carbonized form is termed flexible carbon aerogel (f-CA). These three types of CAs were chosen as they exhibit very different mechanical behavior and properties that were very recently investigated in detail [17].

\section{Materials}

Anhydrous sodium carbonate and resorcinol 98\% were purchased from Aldrich. For f-RF, an aqueous solution of formaldehyde $(37 \% \mathrm{w} / \mathrm{w}$, stabilized with $10 \%$ methanol) from Merck, Germany and for p-RF and s-RF, an aqueous solution of formaldehyde ( $24 \%$ $\mathrm{w} / \mathrm{w}$, not stabilized) from VWR, Germany were used. Acetone (pure, technical grade) was purchased from Th. Geyer, Germany. The $\mathrm{pH}$ values were continuously measured by means of a SevenEasy $\mathrm{pH}$ device with relative accuracy of \pm 0.01 and the $\mathrm{pH}$ electrode InLab ${ }^{\circledR}$ Expert Pro (Mettler Toledo, Germany). The standardized aqueous solution of nitric acid (2 N) was supplied by Alfa Aesar, Germany. Deionized water was used for synthesis. Sealable polypropylene containers of $180 \mathrm{~mL}$ for gelation (with screw-cap) and polypropylene containers of $400 \mathrm{~mL}$ for washing (press-on lid) were purchased from VWR, Germany. The carbon dioxide 4.5 (purity $\geq 99.995 \%$ ) used for supercritical drying was purchased by Praxair, Germany. The argon 4.6 (purity $\geq 99.996 \%$ ) from Praxair, Germany was used for carbonization. Sandpaper made by Norton, Germany was used for grinding.

\section{Synthesis of aerogels}

\section{Synthesis of RF aerogels}

At room temperature, resorcinol $(\mathrm{R})$ was dissolved in deionized water $(\mathrm{W})$ under stirring at $150 \mathrm{rpm}$ using a cross-magnetic stirring bar (Table 1). Then, an aqueous solution of formaldehyde (F) and sodium carbonate $(\mathrm{C})$ was added to the stirred resorcinol solution. After 5 min stirring, the $\mathrm{pH}$ of s-RF and f-RF solutions was adjusted to $5.4-5.6$ by dropwise addition of $2 \mathrm{~N}$ nitric acid. The $\mathrm{pH}$ value of $\mathrm{p}-\mathrm{RF}$ solution was not changed. The stirring at room temperature was continued for $30 \mathrm{~min}$ for $\mathrm{p}-\mathrm{RF}$ and $\mathrm{s}-\mathrm{RF}$ and $60 \mathrm{~min}$ for $\mathrm{f}-\mathrm{RF}$. The homogeneous, transparent solution was placed in a sealable polypropylene container for 7 days for $\mathrm{p}-\mathrm{RF}$ and $\mathrm{f}-\mathrm{RF}$ and 4 days for $\mathrm{s}-\mathrm{RF}$ in an oven at $60^{\circ} \mathrm{C}$ (Memmert $\mathrm{GmbH}$, Germany), as given in Table 1. After the given gelation time, the wet s-RF gel was dried for 1 day at $80^{\circ} \mathrm{C}$ in a drying cabinet (Memmert $\mathrm{GmbH}$, Germany). The $\mathrm{f}-\mathrm{RF}$ and $\mathrm{p}-\mathrm{RF}$ were cooled down to room temperature and transferred into an acetone bath to remove the residual chemicals and to exchange water with acetone being soluble in supercritical carbon dioxide. The acetone was refreshed six times during a span of 3 days. The supercritical drying was carried out with $\mathrm{CO}_{2}$ in an autoclave with volume of $60 \mathrm{~L}$ (Eurotechnica, Germany) at $60{ }^{\circ} \mathrm{C}$ and 100 bars for 3 days (circa $24 \mathrm{~h}$ ). The degassing rate was adjusted to 0.1 bar $\mathrm{min}^{-1}$. 
Table 1 Synthesis parameters of three different types of carbon aerogels

\begin{tabular}{|c|c|c|c|c|c|c|c|c|}
\hline $\begin{array}{l}\text { Type of } \\
\text { aerogel }\end{array}$ & $\begin{array}{l}\mathrm{R}: \mathrm{C} \text { molar } \\
\text { ratio }\end{array}$ & $\begin{array}{l}\mathrm{R}: \mathrm{W} \text { molar } \\
\text { ratio }\end{array}$ & $\begin{array}{l}\mathrm{R}: \mathrm{F} \text { molar } \\
\text { ratio }\end{array}$ & $\begin{array}{l}\mathrm{pH} \text { of initial } \\
\text { solution }\end{array}$ & $\begin{array}{l}\text { Stirring time } \\
(\mathrm{min})\end{array}$ & $\begin{array}{l}\text { Gelation time } \\
\text { (days) }\end{array}$ & $\begin{array}{l}\text { Drying } \\
\text { conditions }\end{array}$ & $\begin{array}{l}\text { Pyrolysis } \\
\text { conditions }\end{array}$ \\
\hline $\mathrm{p}-\mathrm{CA}$ & 200 & 0.019 & 0.5 & 7.0 & 30 & 7 & $\begin{array}{l}\text { Super critical } \\
\mathrm{CO}_{2}\end{array}$ & $\begin{array}{l}1000{ }^{\circ} \mathrm{C}, 1 \mathrm{~h}, \\
\mathrm{Ar}\end{array}$ \\
\hline $\mathrm{s}-\mathrm{CA}$ & 1500 & 0.044 & 0.74 & $5.4-5.6$ & 30 & 4 & $\begin{array}{l}\text { Ambient } \\
\text { pressure } 80{ }^{\circ} \mathrm{C}\end{array}$ & $\begin{array}{l}1000{ }^{\circ} \mathrm{C}, 1 \mathrm{~h}, \\
\mathrm{Ar}\end{array}$ \\
\hline $\mathrm{f}-\mathrm{CA}$ & 50 & 0.008 & 0.5 & $5.4-5.6$ & 60 & 7 & $\begin{array}{l}\text { Super critical } \\
\mathrm{CO}_{2}\end{array}$ & $\begin{array}{l}1000^{\circ} \mathrm{C}, 1 \mathrm{~h}, \\
\mathrm{Ar}\end{array}$ \\
\hline
\end{tabular}

\section{Carbonization}

The carbonization was carried out in an electric furnace (Standardofen "F(A)," Gero Hochtemperaturöfen $\mathrm{GmbH}$, Germany) using argon. The resulting RF aerogels were placed in the furnace, purged three times with argon, and heated to the carbonization temperature of $1000{ }^{\circ} \mathrm{C}$. The heating rate was adjusted to $6-7 \mathrm{~K} \mathrm{~min}^{-1}$, the pressure in oven was adjusted to 50 mbar. After $60 \mathrm{~min}$ at these conditions, the samples-carbon aerogels-were cooled down to room temperature under the flow of argon.

\section{Grinding and milling parameters}

For pulverization, three different methods were used: manual grinding with sandpapers, milling in a shaker cryo-mill and milling in a planetary ball mill. The grit designation P150 was used for the p-CA and the s-CA and for the f-CA P1000 (the higher the number is, the finer the sand particles on the sandpaper). The powder which was produced through the grinding was collected and analyzed. For milling in a shaker cryo-mill, 6850 Freezer/Mill (SPEX CertiPrep, U.S.A.) was used. All samples were milled 20 times for $2 \mathrm{~min}$ while being cooled with liquid nitrogen at $77 \mathrm{~K}$. Between each repetition, a break of 1 min was taken. For milling in a planetary ball mill, PULVERISETTE 7 (FRITSCH GmbH, Germany) with 16 zirconia balls and $700 \mathrm{rpm}$ was used. The milling time and the number of repetitions (as shown in Table 2) were varied. Due to different mechanical properties of the synthesized carbon aerogels-from very soft to stiff and ductile- the milling duration and the number of repetitions vary for different aerogels. The samples were milled until a homogeneous powder was observed. The homogeneity of powder was estimated
Table 2 Milling parameters for planetary ball mill

\begin{tabular}{lll}
\hline Sample & Milling time (min) & Number of repetitions \\
\hline p-CA ball mill 1 & 7 & 1 \\
p-CA ball mill 2 & 7 & 2 \\
s-CA ball mill 1 & 5 & 3 \\
s-CA ball mill 2 & 7 & 3 \\
f-CA ball mill 1 & 5 & 3 \\
f-CA ball mill 2 & 7 & 2 \\
\hline
\end{tabular}

with the naked eye. The size of powder particles was compared; if some large granules could be observed, the milling was continued or repeated until the particles are of the same size. Between each repetition, a break of 3 min was taken.

\section{Characterization of carbon aerogels}

The skeletal densities were measured using an AccuPyc instrument based on a displacement measurement technique (Micromeritics, Germany). The specific surface area, mesopore size distribution, mesopore volume, and micropore volume of aerogels were determined at $77 \mathrm{~K}$ by means of the nitrogen adsorption-desorption isotherms, and the calculations were based on methods BET/DFT/t-plot (TriStar II, Micromeritics, Germany). For t-plot, a Carbon Black STSA model was used. The micropore size distribution was analyzed by using carbon dioxide adsorption at $273 \mathrm{~K}$ and calculated with DFT model $\left(\mathrm{CO}_{2}\right.$-DFT model). Before analysis, the samples were outgassed for $12 \mathrm{~h}$ at $200{ }^{\circ} \mathrm{C}$ and 0.1-0.5 mbar. The microstructure of the aerogels was investigated using a scanning electron microscope (Zeiss Merlin, Germany) and a transmission electron microscope (Philips Tecnai F30). Prior to SEM measurements, the carbon aerogels were coated with 
platinum for $90 \mathrm{~s}$ at $16 \mathrm{~mA}$. For TEM investigations, monolithic carbon aerogels were pulverized with a pestle, mixed with $99.9 \%$ isopropanol and applied to a TEM grid (R2/1 Cu $200 \mathrm{Mesh}$ ). Wide-angle X-ray scattering (WAXS) measurements were performed using an $X^{\prime}$ Pert Pro powder diffractometer from PANalytical with $\mathrm{Cu}$ Ka radiation $(\lambda=1.5418 \AA)$ at $40 \mathrm{kV}$ and $40 \mathrm{~mA}$. The powder samples were flattened on a silicon single-crystal sample holder to a thickness of $1 \mathrm{~mm}$. The fitting of the WAXS data was performed according to the theoretical scattering function model developed by Ruland and Smarsly, using the Wolfram Mathematica 11 software. The parameters were manually adjusted first, followed by an automatic optimization using the Nonlinear Model Fit function implemented in Mathematica 11. The experimental data were not altered for the fitting, i.e., no background was subtracted.

A Senterra Raman microscope (Bruker Optics) with a 100xobjective, a Nd:YAG laser $(\lambda=532 \mathrm{~nm}$, $P=2 \mathrm{~mW}$ ), and a charge couple device (CCD) were used for Raman measurements. The solid samples were measured on a glass substrate at room temperature, and an integration time of $5 \mathrm{~s}$ and 20 coadditions was used. In order to determine the intensity height of the bands, the Raman spectra were fitted with two profiles, namely an asymmetrical Breit-Wigner-Fano (BWF) profile for the G band and a symmetrical Lorentzian profile for the $\mathrm{D}$ band.

TG-MS measurements were performed with a Netzsch STA 409 PC/PG under synthetic air, a heating rate of $5 \mathrm{~K} \mathrm{~min}^{-1}$ and an end temperature of $800{ }^{\circ} \mathrm{C}$.

Elemental analysis was conducted using a Vario EL from Elementar for the determination of the carbon content.

\section{Results and discussion}

In this chapter, first the microscopy images of monolithic and powdered samples are discussed, and then the changes in skeletal density and specific surface area based on gas sorption measurements. This is followed by discussions on pore volumes and pore sizes as well as on the microstructure on a nanometer scale.

Figure 2 gives an overview about the microstructure of ductile monolithic and pulverized p-CA samples. Figure $2 \mathrm{a}$ depicts a part of monolithic sample. The powder produced by grinding is shown in Fig. $2 b$. The powder consists of granules with different sizes from very large of about $30-40 \mu \mathrm{m}$ to small of $1 \mu \mathrm{m}$. The granules exhibit undefined very irregular shape. The powder generated in shaker cryo-mill consists of spherical, small granules of about $1 \mu \mathrm{m}$. Larger granules seem to be formed through the agglomeration of smaller particles. Possibly, the agglomerates were formed by impact of steel bar on already existing small granules. The mill duration of $20 \mathrm{~min}$ appears to be too long to achieve homogeneity of granules sizes. In comparison, the granules of $7 \mathrm{~min}$ ball-milled sample (Fig. $2 \mathrm{~d}$ ) are in average smaller than grinded with broad distributed granules sizes. The doubled number of repetition in the ball mill led to higher homogeneity, but still some large parts are seen in Fig. 2e. Some of the particles are flat probably due to plastic deformation. A further increase in milling time or number of repetition is necessary to produce homogeneous granule size of ductile aerogels.

The TEM image analysis shows very clear changes in the morphology after grinding and milling. Figure $3 a$ depicts the initial structure of $\mathrm{p}$-CA. After grinding the structure of $\mathrm{p}-\mathrm{CA}$ is fluffier, large pores are seen in Fig. $3 \mathrm{~b}$. The frictions during grinding loosen the structure, and it appears more porous compared to the compact, original structure. The structure of p-CA milled in shaker cryo-mill exhibits nearly no differences compared to initial aerogel structure. Figure $3 d$, e shows the structures of p-CA milled in a planetary ball mill. Remarkable is that both structures became compacter, a densification of network took place and with doubled number of repetition (Fig. 3e) the degree of densification increased.

The powders of s-CA show some similarity to p-CA. They consist of spherical particles of about $2-3 \mu \mathrm{m}$ and macropores as shown in Fig. 4a. The network of grinded sample (Fig. $4 \mathrm{~b}$ ) shows changes, as the fracture surfaces of particles are visible, and a high number of particles are disconnected. Additionally, very small particles are visible. Also, similar to $\mathrm{p}-\mathrm{CA}$, the grinding method produced inhomogeneous powder. The structure of the powder produced in the shaker cryo-mill differs very strongly from others. The spherical particles of the original structure disappeared completely; the powder consists of very small granules, even the low-energy method destroyed the original structure completely. The 
Figure 2 SEM images of ductile carbon aerogel (p-CA): a a piece of monolithic sample with some small nugget formed during sample preparation, $\mathbf{b}$ inhomogeneous powder created by means of grinding with sand paper, c aggregation of granules caused by repeated, frequent impacts in shaker cryo-mill, d aerogel powder from planetary ball mill

$(7 \mathrm{~min} \times 1)$ consist of granules with different sizes and shapes, e increased number of repetitions leads to homogeneous powder produced in planetary ball mill $(7 \min \times 2)$.
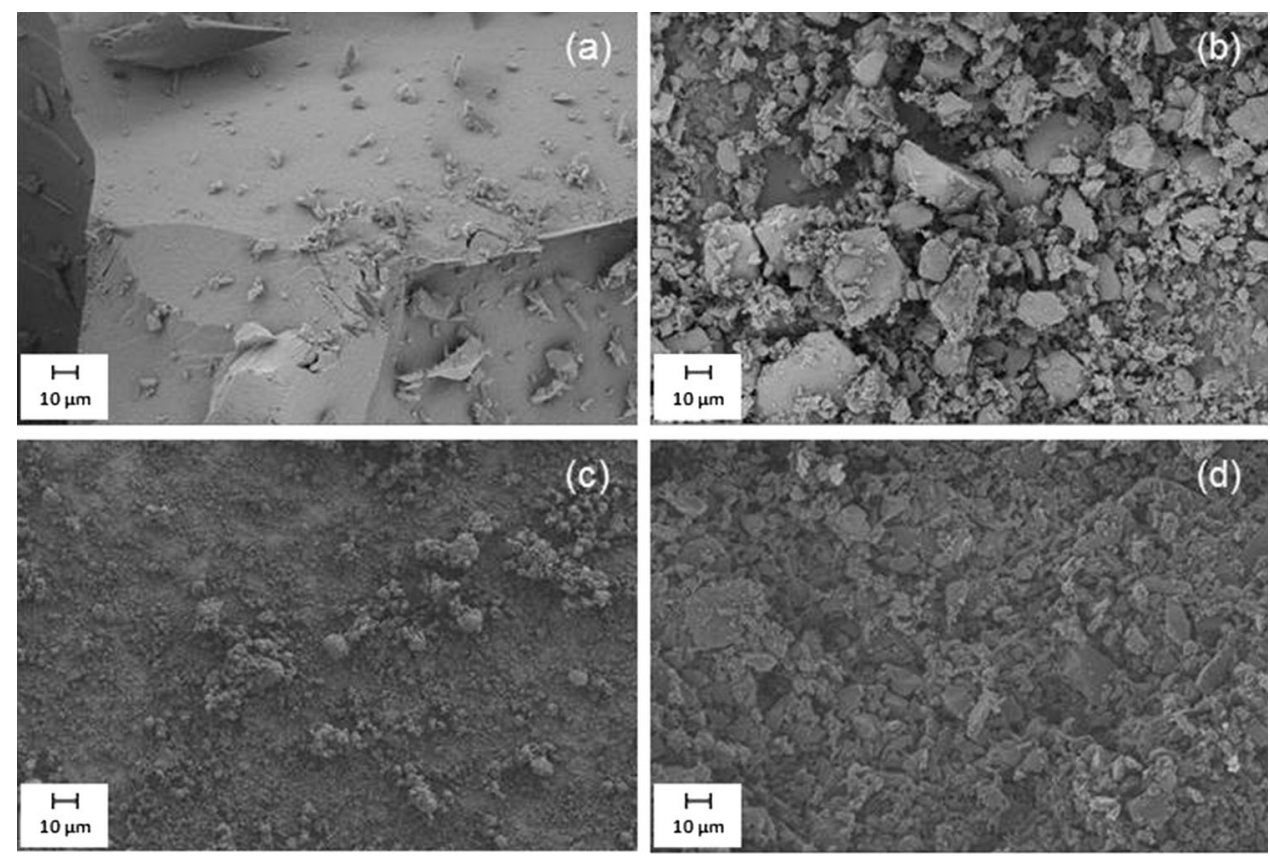

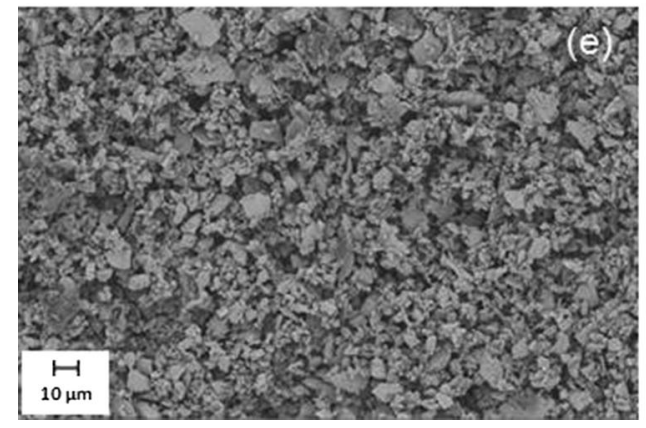

powder of s-CA produced with planetary ball mill appeared less homogeneous (ball mill 1) when observed with a naked eye after $5 \mathrm{~min}$ and 3 repetitions. Therefore, the milling duration was increased to $7 \mathrm{~min}$ for the second experiment (ball mill 2) while keeping the number of repetitions constant. Increasing of milling time led to higher homogeneity of the powder; however, the sizes of particles remain very different. Further increase in milling duration is necessary.

The morphology of aerogels investigated in TEM correlates with SEM observations. Monolithic (Fig. 5a) and grinded (Fig. 5b) structures look similar, but in Fig. $5 \mathrm{~b}$ some small granules are visible in addition to a large particle. In contrast, particles of the cryo-milled powder seem to be denser (Fig. 5c). Slight densification took place due to frequent, powerful impacts. Higher number of smaller granules was generated by the use of the ball mill.
Figure $5 \mathrm{~d}$ and e clearly shows increased number of smaller granules after prolonged milling time.

The networks of monolithic and grinded f-CA powder show no visible changes as depicted in Fig. $6 a$ and $b$, which is expected upon the use of lowenergy method. The impacts encountered in the shaker cryo-mill produced powder consisting of smaller granules than the one obtained by a ball mill. Nevertheless, large and compact agglomerates could be observed (Fig. 6c). The planetary ball milling programs, 5 min with 3 repetitions (ball mill 1) and 7 min with 2 repetitions (ball mill 2), led to very fluffy powder. Figure $6 \mathrm{~d}$ and e shows large, dense agglomerates. Due to almost equal milling time, the microstructure of both samples does not differ. Nevertheless, compared to grinded and monolithic samples, these inhomogeneous powders consist of large compact granules. Surprisingly, almost no visible changes in the structure could be seen on SEM images with higher magnification (Fig. 15). 

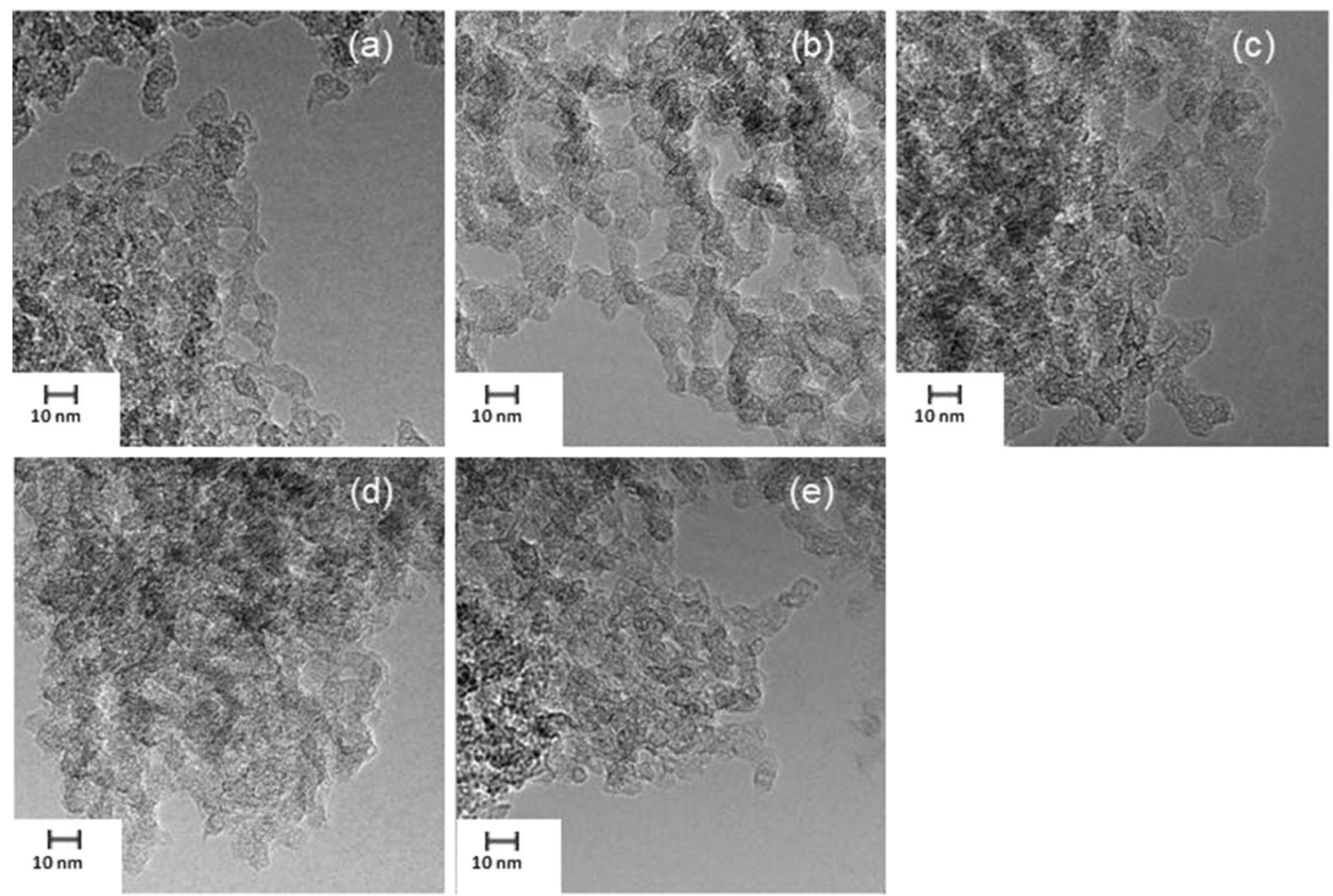

Figure 3 TEM images of ductile carbon aerogel (p-CA): a Monolithic sample consisting of small pores and small particles, $\mathbf{b}$ the structure of grinded sample appears to be more fluffily than monolithic sample, $\mathbf{c}$ the structure of shaker cryo-

TEM images of f-CA samples are shown in Fig. 7. Compared to monolithic sample (Fig. 7a), the boundaries of grinded particles are indistinct (Fig. 7b). This appearance was not observed for other samples. The structure of cryo-milled and ball-milled samples appears to be denser compared to monolithic sample. The particles of milled samples appear to be smaller than those of monolithic samples.

Summing up, the p-CA, compared to $\mathrm{f}-\mathrm{CA}$ and s-CA, consists of small particles and the most of pores are mesopores. In contrast, s-CA and f-CA have larger particles and micro- and macropores-bimodal pore size distribution.

The properties of studied carbon aerogels are summarized in Table 3 and for better comparison are graphically presented in Fig. 8 .

The skeletal density as measured by means of helium pycnometry is plotted in Fig. 8a. Typical skeletal densities of amorphous carbons are between 1.8 and $2.2 \mathrm{~g} \mathrm{~cm}^{-3}$ [18]. All of investigated samples exhibit skeletal density in that region; no noticeable changes were observed. milled samples looks similar to the original, $\mathbf{d}$ after one planetary ball mill cycle $(7 \mathrm{~min} \times 1)$ the structure is compact, the pores are difficult to differ, e two milling cycles $(7 \mathrm{~min} \times 2)$ lead to more compact, densified structure.

Specific surface areas of samples are given in Fig. $8 \mathrm{~b}$. The surface area of s-CA was not changed by pulverization and is around $627 \mathrm{~m}^{2} \mathrm{~g}^{-1}$. Noticeable changes in surface area of $\mathrm{p}-\mathrm{CA}$ and $\mathrm{f}-\mathrm{CA}$ were observed: after grinding, surface area increased about $33 \%$ for $\mathrm{p}$-CA and $48 \%$ for f-CA. After ball milling, the increase is lower of about $14 \%$ for p-CA and $25 \%$ for $\mathrm{f}-\mathrm{CA}$.

The pore volumes play an important role for different applications (lithium-sulfur batteries, foundry or as adsorption materials) and are shown in Fig. 8c, $\mathrm{d}$. The effect of pulverization on meso- and micropore volumes is significant and correlates well with changes in the surface area. Brittle p-CA exhibit almost doubled meso- and micropore volumes after grinding. Furthermore, with higher energy impact the pore size distribution was changed drastically: the ratio of micropores decreases and the ratio of mesopores increases. In the case of s-CA, only a slight increase in mesopore volume after cryo-milling could be detected. 
Figure 4 SEM images of stiff carbon aerogel (s-CA):

a monolithic sample consisting of spherical particles of about 2-3 $\mu \mathrm{m}$ and macropores, $\mathbf{b}$ the structure of grinded sample shows fracture surfaces of particles and a high number of disconnected particles, $\mathbf{c}$ in shaker cryo-mill the spherical particles disappeared and the powder consists of very small granule, $\mathbf{d}$ aerogel powder from planetary ball mill $(5 \min \times 3)$ consist of granules with different sizes and shapes, e increased milling duration leads to higher homogeneity of granule sizes produced in planetary ball mill $(7 \mathrm{~min} \times 3)$.
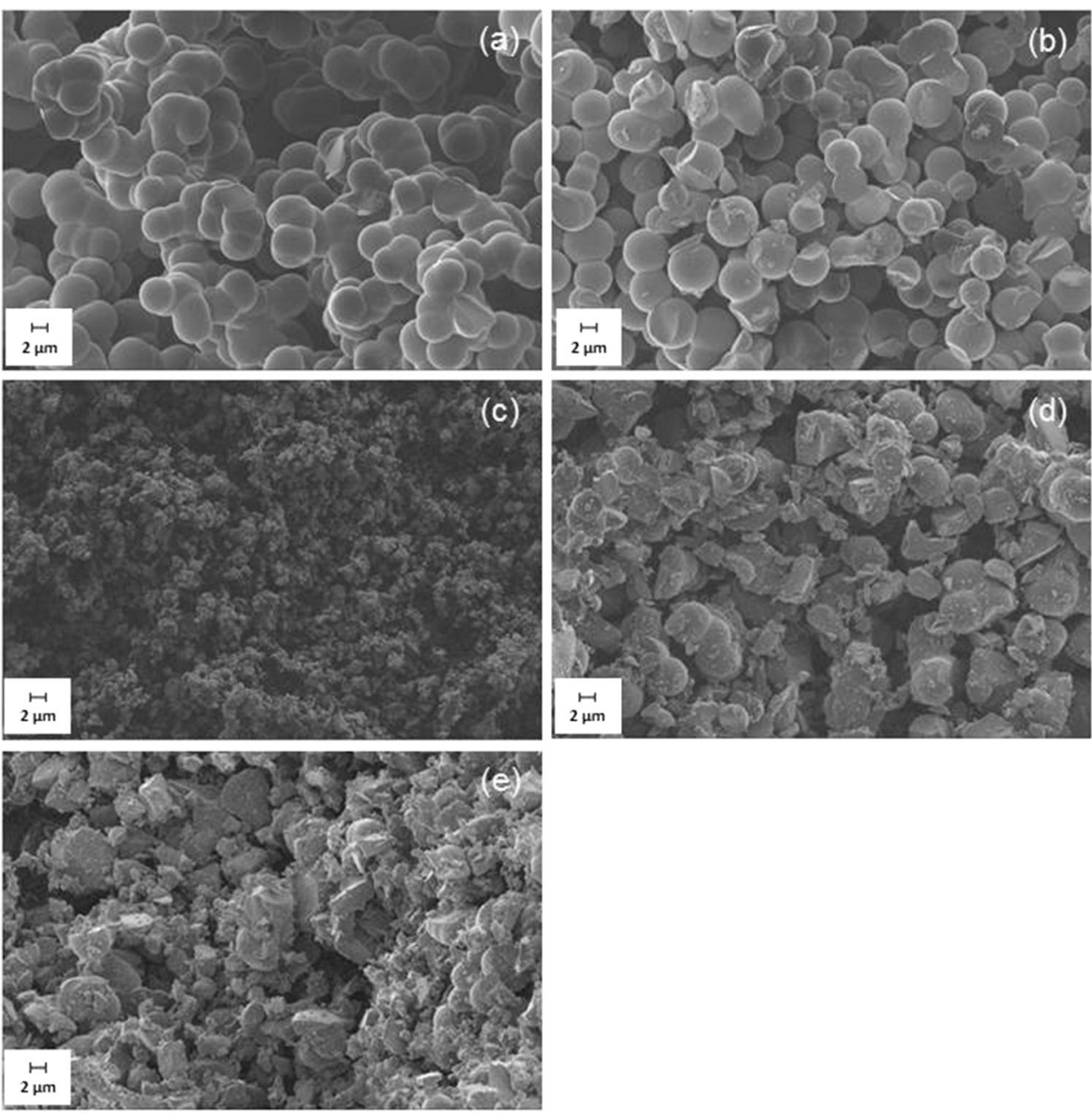
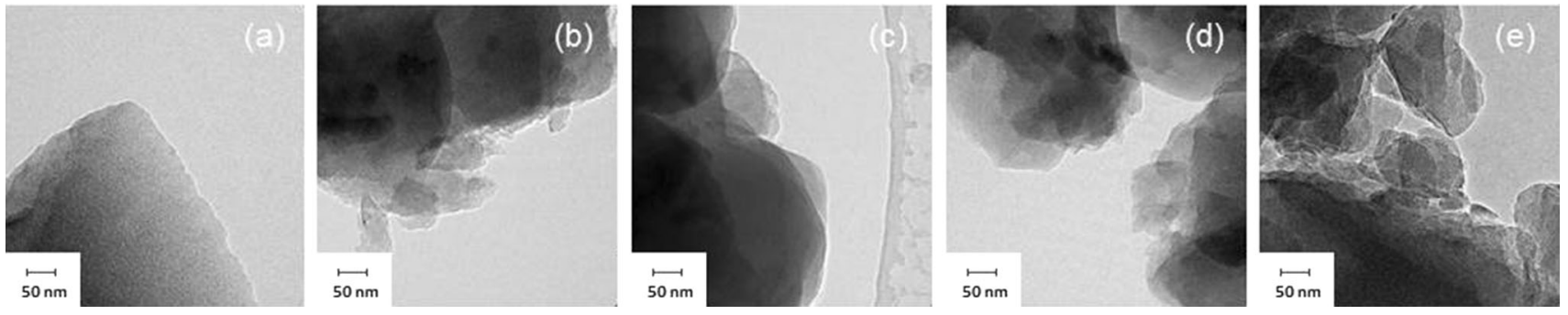

Figure 5 TEM images of stiff carbon aerogel (s-CA): a structure of monolithic sample, $\mathbf{b}$ the grinded sample shows some small granules together with a large particle, $\mathrm{c}$ the particles of shaker

The f-CA samples show also manifold increase in both meso- and micropore volumes. In conclusion, during pulverization additional micro- and mesopores were generated. Surprisingly, low-energy grinding causes the highest rise of micropore volume, the energy intensive milling methods induced formation of mesopores. cryo-milled powder seem to be denser, $\mathbf{d}$ the use of planetary ball mill generate a higher number of small granules, $\mathbf{e}$ the number of small granules increases with prolonged milling time.

The adsorption isotherms of carbon aerogels are aerogels can be easily distinguished. Ductile p-CA exhibits a type IV isotherm which is typical for mesoporous aerogels. The adsorption hysteresis loop increased with longer milling time and higher energy impact. The steep and narrow loop may be a sign of delayed condensation on the adsorption branch. This shown in Fig. 9. The isotherm types for the different 
Figure 6 SEM images of flexible carbon aerogel (f-CA): a original structure of monolithic sample, $\mathbf{b}$ grinded sample shows similar structure, $\mathbf{c}$ the shaker cryomilled powder consists of small granules and large agglomerates, $\mathbf{d}$ powder after milling in planetary ball mill (ball mill 1) and e after prolonged time (ball mill 2) shows large and dense agglomerates.
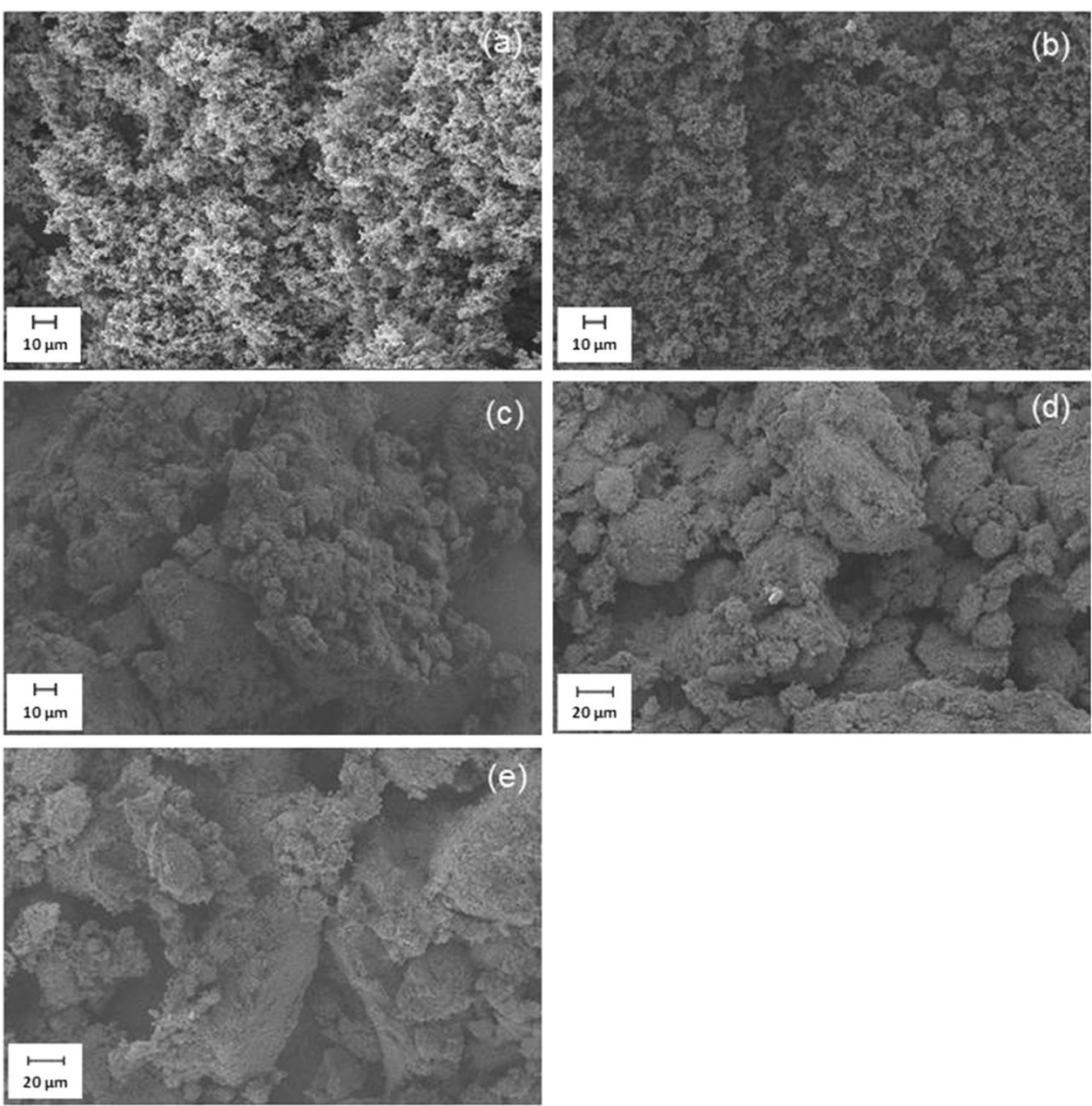
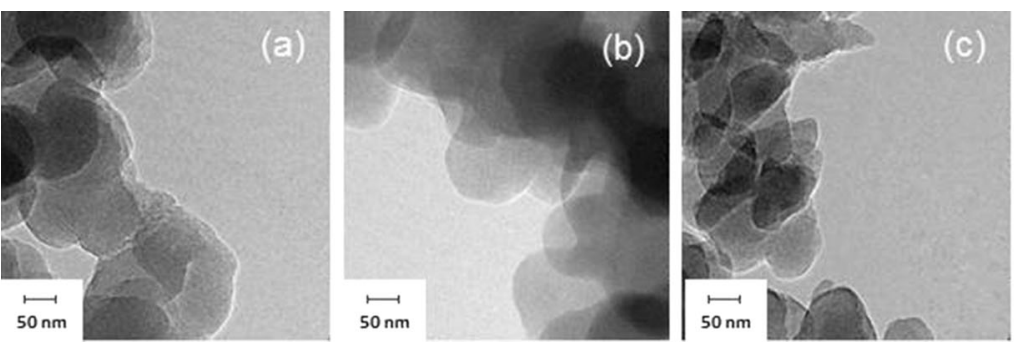

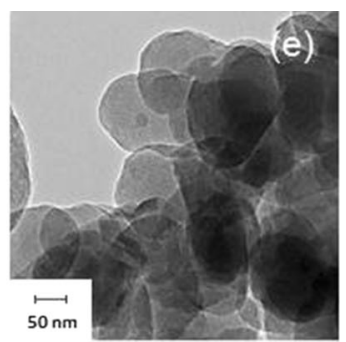

smaller and denser than of monolithic sample, $\mathbf{d}$ the structure of the planetary ball-milled sample $(5 \min \times 3)$ appears to be more dense than the monolithic sample, e planetary ball-milled sample $(7 \mathrm{~min} \times 2)$ shows a denser structure.

- Monolithic, grinded, and ball-milled samples exhibit type Ia isotherm which is typical for microporous materials with small external surface area. A steep uptake at low relative pressure is due to the enhanced adsorbent-adsorptive interactions in micropores.

The stiff s-CA samples show two different adsorption isotherms: 
Table 3 Properties of monolithic and pulverized carbon aerogels

\begin{tabular}{lllllll}
\hline Properties & & Monolithic sample & Sand paper & Shaker cryo-mill & Planetary ball mill 1 & Planetary ball mill 2 \\
\hline Skeletal density $\left(\mathrm{g} \mathrm{cm}^{-3}\right)$ & p-CA & $2.16 \pm 0.02$ & $2.34 \pm 0.05$ & $2.10 \pm 0.07$ & $2.38 \pm 0.02$ & $2.40 \pm 0.01$ \\
& s-CA & $2.24 \pm 0.04$ & $2.07 \pm 0.09$ & $2.01 \pm 0.06$ & $2.12 \pm 0.08$ & $2.16 \pm 0.09$ \\
& f-CA & $2.12 \pm 0.03$ & $2.41 \pm 0.04$ & $2.17 \pm 0.08$ & $2.05 \pm 0.03$ & $2.06 \pm 0.03$ \\
Surface area $\left(\mathrm{m}^{2} \mathrm{~g}^{-1}\right)$ & p-CA & $689 \pm 2$ & $915 \pm 2$ & $717 \pm 2$ & $775 \pm 3$ & $692 \pm 2$ \\
& s-CA & $625 \pm 1$ & $628 \pm 1$ & $627 \pm 1$ & $627 \pm 1$ & $631 \pm 1$ \\
& f-CA & $561 \pm 0.5$ & $821 \pm 1$ & $781 \pm 1$ & $721 \pm 1$ & $689 \pm 1$ \\
Micropore volume $\left(\mathrm{cm}^{3} \mathrm{~g}^{-1}\right)$ & p-CA & 0.09 & 0.16 & 0.13 & 0.15 & 0.12 \\
& s-CA & 0.21 & 0.21 & 0.21 & 0.22 & 0.20 \\
& f-CA & 0.18 & 0.26 & 0.24 & 0.23 & 0.22 \\
Mesopore volume $\left(\mathrm{cm}^{3} \mathrm{~g}^{-1}\right)$ & p-CA & 0.81 & 1.36 & 1.84 & 0.92 & 0.01 \\
& s-CA & 0.01 & 0.01 & 0.05 & 0.13 & 0.01 \\
& f-CA & 0.04 & 0.06 & 0.31 & 0.21 \\
\hline
\end{tabular}

(a)

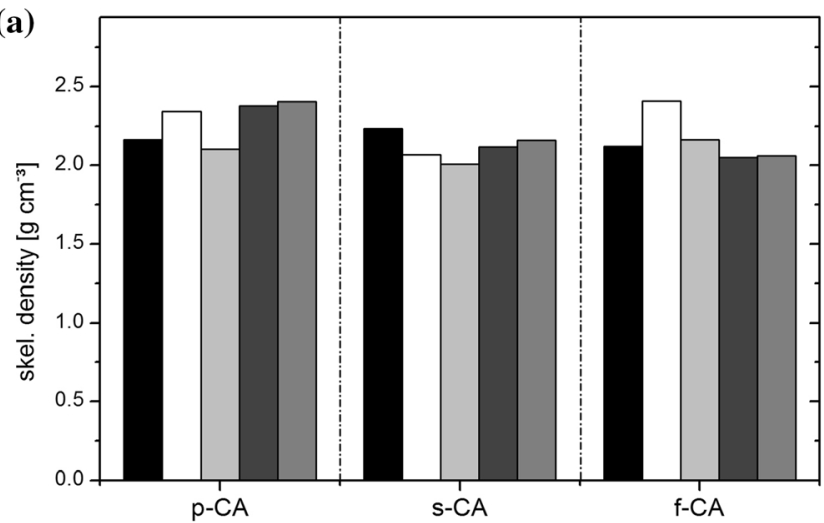

(c)

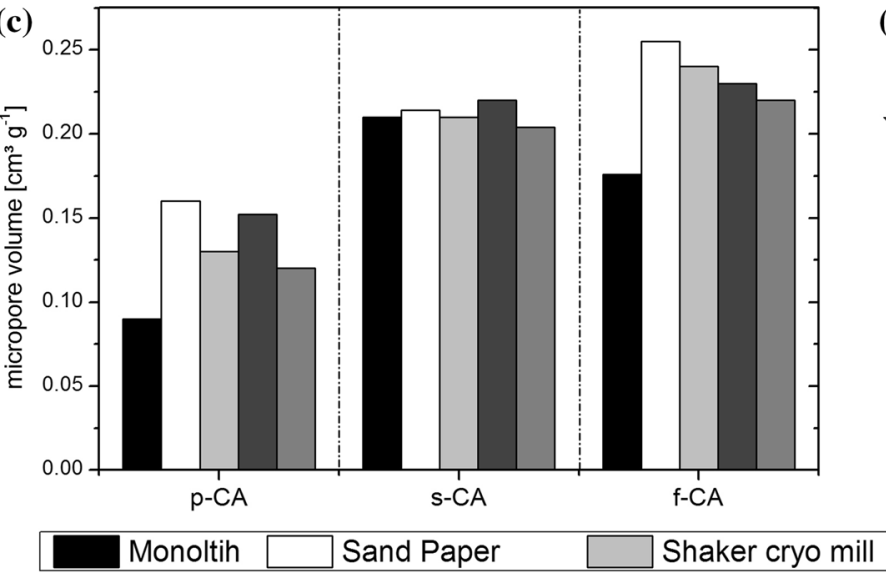

(b)

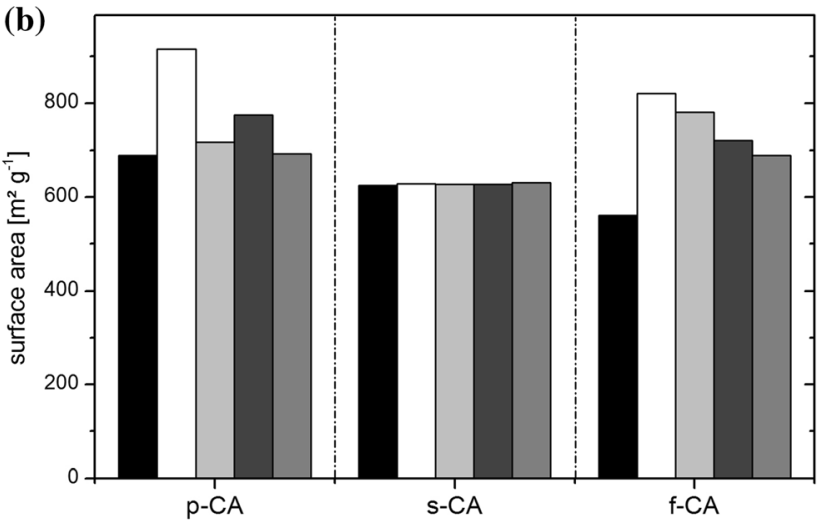

(d)

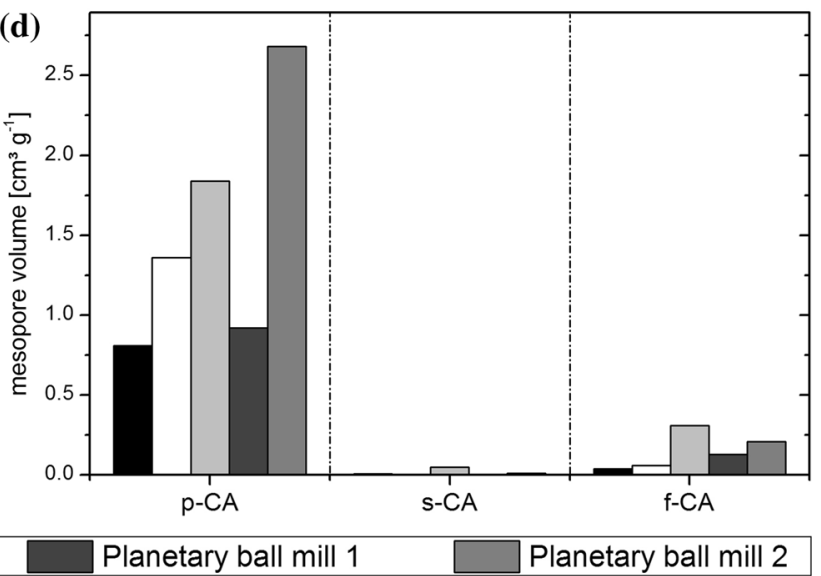

Figure 8 Properties of studied carbon aerogels before and after pulverization: a skeletal density; $\mathbf{b}$ surface area; $\mathbf{c}$ micropore volume, and d mesopore volume.

- Sample milled in the shaker mill exhibits isotherm of type IV showing small hysteresis at high relative pressure. The hysteresis is in agreement with raised mesopore volume.
The isotherms of flexible carbon aerogels differ depending on pulverization method:

- Monolithic and grinded samples exhibit type Ia isotherm similar to s-CA. The isotherm of grinded 
(a)
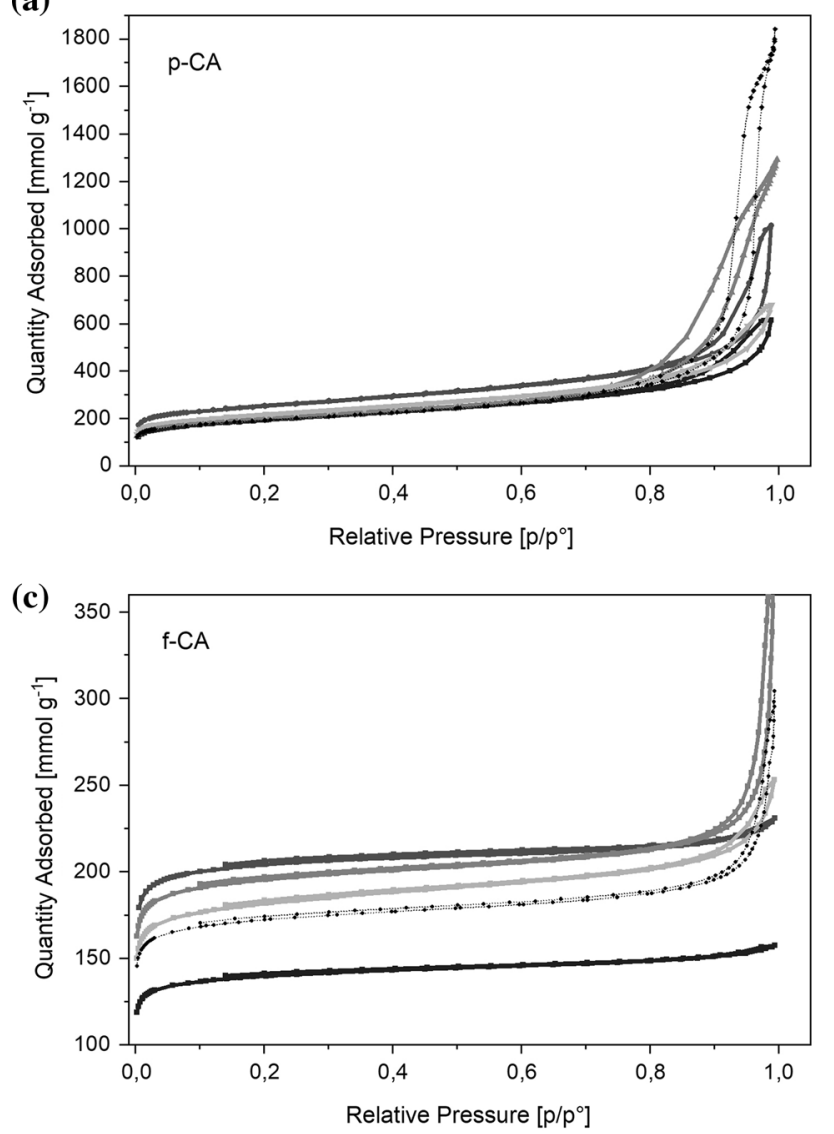

(b)

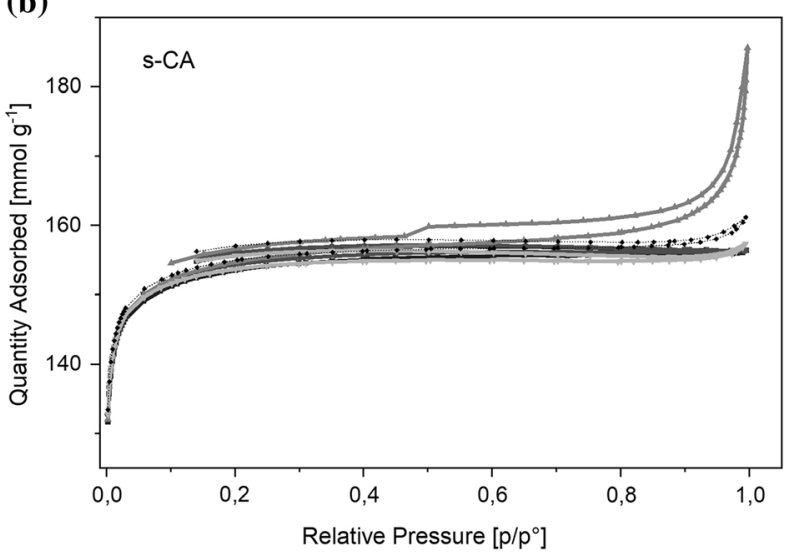

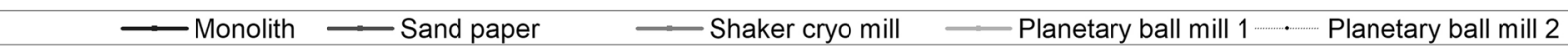

Figure 9 Adsorption isotherms $\left(\mathrm{N}_{2}, 77 \mathrm{~K}\right)$ of a ductile, mesoporous p-CA; b microporous stiff s-CA, and $\mathbf{c}$ flexible, microporous carbon aerogel.

powder sits above the monolithic sample which is caused by higher micropore volume.

- Isotherms of milled samples are type VI; they show small hysteresis at high relative pressure. It could be considered that with higher energy impact the mesopore volume increases drastically.

Figure 10 shows the dependence of pulverization methods on the pore size distribution. The results correlate with changes in isotherms and micro- and mesopore volumes. Ductile p-CA, as already shown in Table 3, is a mesoporous aerogel with a small amount of micro pores. The grinding caused an increase in the number of pores between 20 and $50 \mathrm{~nm}$. Additionally, pore numbers of about $0.9 \mathrm{~nm}$ increased drastically. In contrast, after shaker milling, the pores became smaller with average values between 10 and $30 \mathrm{~nm}$. Surprisingly, for ball mill 1, no valuable changes could be observed. However, ball mill 2 shows significant changes. A narrow pore size distribution can be observed. Summing up, the original structure of p-CA was modified drastically.

Microporous s-CA shows only a minor modification after milling in shaker cryo-mill in the mesopore region. In comparison with monolithic samples, the pores became slightly larger from approximately $2-3 \mathrm{~nm}$ to $3-4 \mathrm{~nm}$. Additionally, pores in the region between 20 and $50 \mathrm{~nm}$ appear. In the micropore region, no noticeable changes could be seen. The structure of initially microporous f-CA was changed as well, during pulverization. After grinding and shaker milling, amount of $2 \mathrm{~nm}$ pores increased, whereas after ball milling, an additional peak appeared in the region between 30 and $50 \mathrm{~nm}$.

The WAXS data in Fig. 11 show the typical scattering maxima of turbostratic carbons. There are only 
(a)

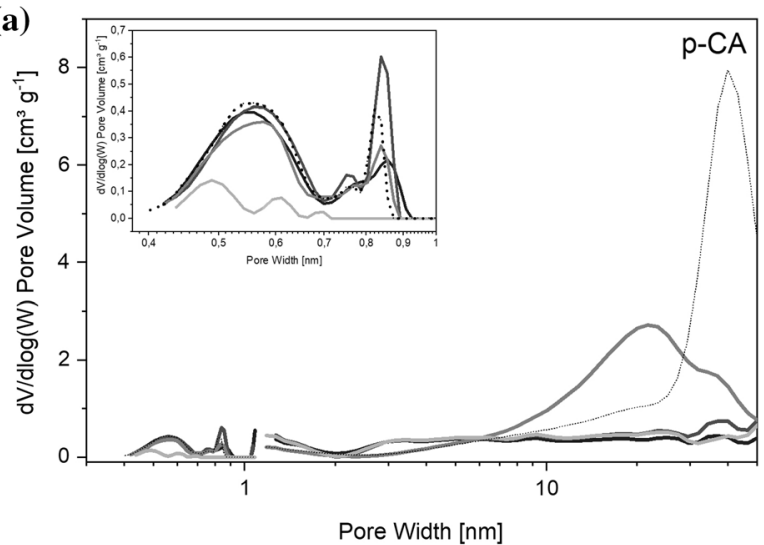

(c)

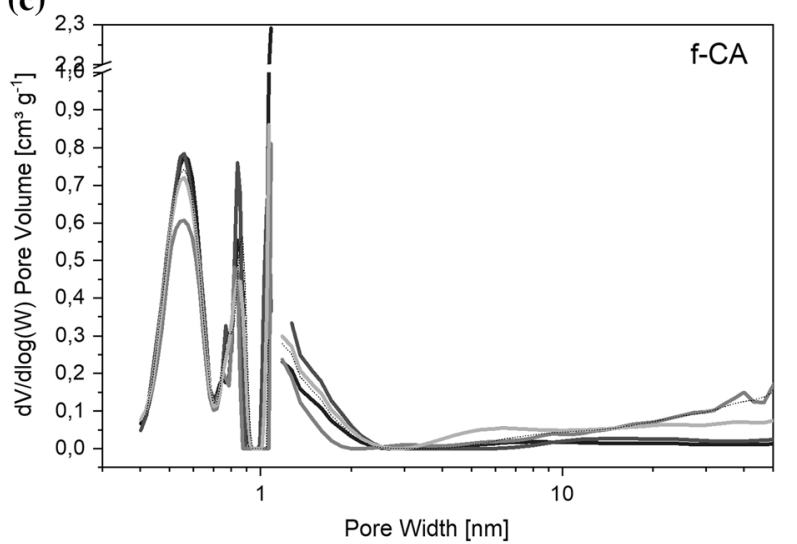

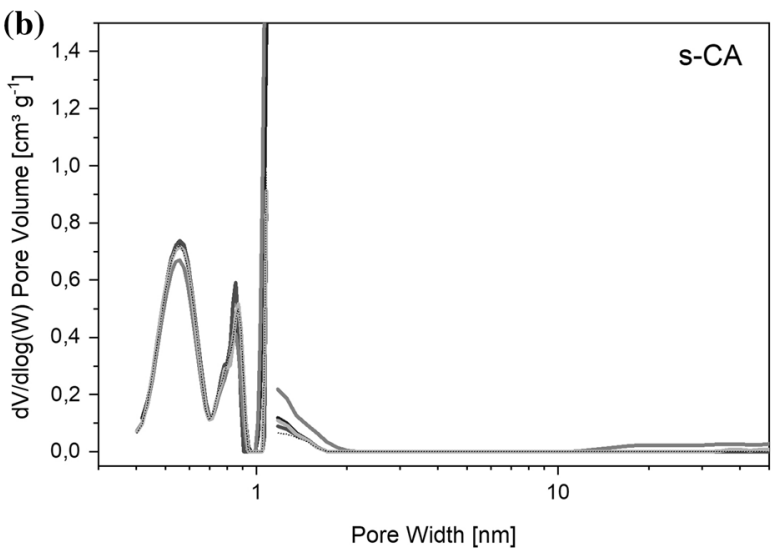

Figure 10 Pore size distributions of a ductile, mesoporous p-CA; b microporous stiff s-CA, and c flexible, microporous carbon aerogel. By usage of DFT model for micro- and mesopore region, the pore sizes were calculated. Due to different gases used, a gap between 1 and $1.5 \mathrm{~nm}$ appears. three very broad reflexes detectable in the whole $2 \theta$ range from $10^{\circ}$ to $100^{\circ}$. The origin of these reflections is different due to the layer structure of the carbon aerogels. The (002) reflections arises due to the interlayer scattering between parallel stacked carbon layers. The (10) and (11) reflections correspond to the intralayer scattering within the graphene layers. An additional impurity reflection at $27^{\circ}$ is seen especially for $\mathrm{p}-\mathrm{CA}$ and $\mathrm{f}-\mathrm{CA}$, which can be contributed to trapped $\mathrm{Na}_{2} \mathrm{CO}_{3}$ from synthesis. The amount of catalyst for those samples was higher than for s-CA. The microstructure of the carbon aerogels is investigated by an advanced wide-angle X-ray scattering approach. Since standard scattering evaluation methods like single peak analysis or Rietveld refinement suffer from the turbostratic arrangement of the carbon stacks and do not achieve meaningful results, a novel approach similar to Rietveld refinement is used.

The algorithm by Ruland and Smarsly is capable of fitting the entire wide-angle scattering curve of turbostratic carbons [19-25]. Physically meaningful parameters like the average graphene layer size $L_{a}$ the average stack height $L_{c}$, the average interlayer distance $a_{3}$, and disorder parameter describing the disorder within the layers $\sigma_{1}$ and between the layers $\sigma_{3}$ are directly quantified and can be compared to each other. The fit of the scattering curve is excellent and in a very good agreement with the experimental data (Fig. 12), which lead to valid results (Fig. 13).

The WAXS data show minor differences regarding stacking of graphene layers in all aerogels. Compared to the initial monolithic carbon aerogels, the average graphene layer size $L_{a}$ of the treated samples decreases during pulverization from 25 to $16 \AA$ 
Figure 11 WAXS data of ductile, mesoporous p-CA; microporous stiff s-CA, and flexible, microporous f-CA.

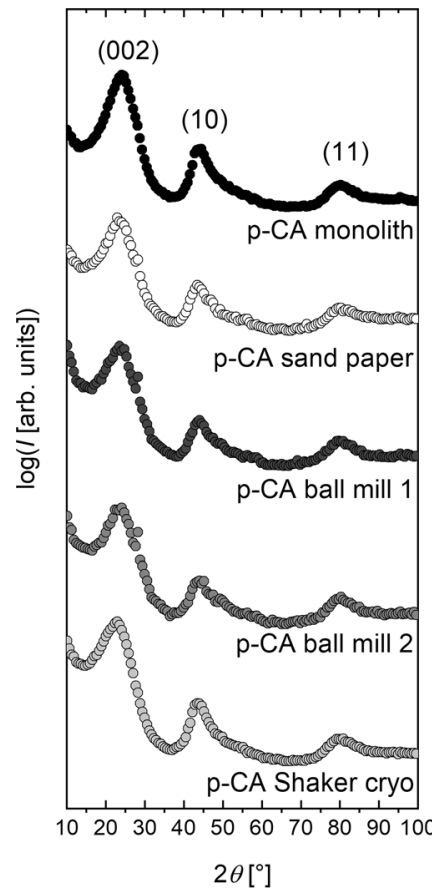

$2 \theta\left[{ }^{\circ}\right]$
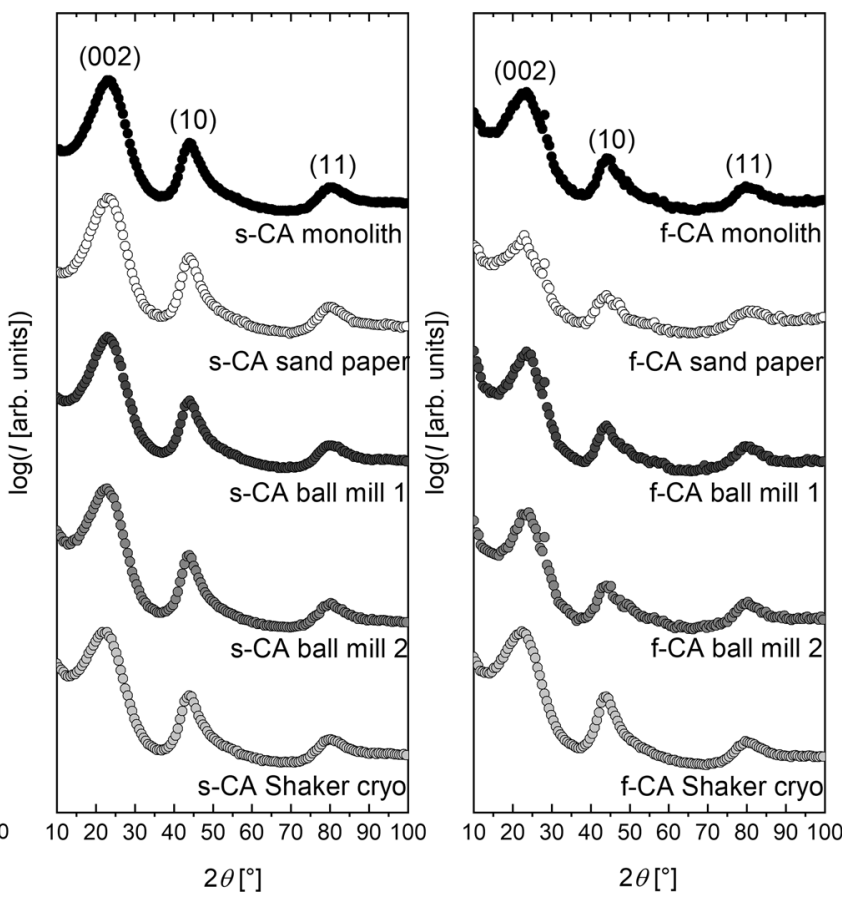

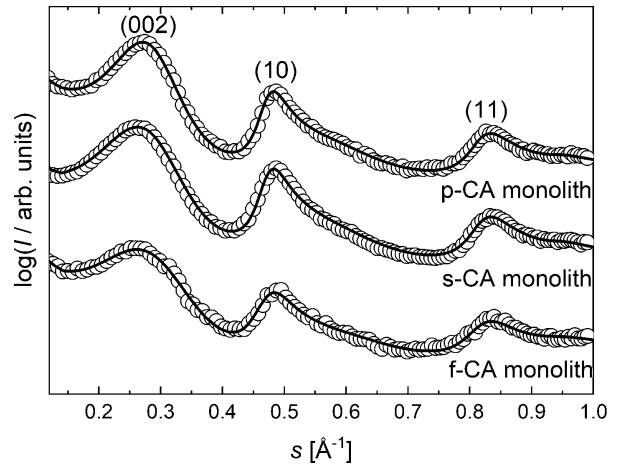

Figure 12 Fit of the initial, monolithic CA samples by the model of Ruland and Smarsly.

(Fig. 13a). The layer size is reduced with longer ball milling time, too. Overall, the ball milling samples show the lowest $L_{a}$ values and the flexible f-CA samples exhibit smaller layers compared to the ductile p-CA and stiff s-CA samples. The value of the disorder parameter $\sigma_{1}$ is about 0.11 and is constant for all samples. We conclude, the milling of samples reduced the graphene layer size, but the average structural disorder within graphene layers did not change. The applied energy was too low for a reorganization of the graphene structure, which is expectable.

The average stack heights of graphene $L_{c}$ just slightly decrease from overall $9 \AA$ to $6 \AA$. The cryomilled samples show the lowest values compared to the other materials. The average interlayer distance $a_{3}$ is about $3.55-3.67 \AA$, which is typical for non-graphitic carbon. Generally, aerogels do not show a significant change of the spacing. The standard deviation of the interlayer spacing $\sigma_{3}$ is very low about $0.1 \AA$, which described ordered stacking of the graphene layers.

The Raman spectra in Fig. 14 show two pronounced bands. The disorder induced $\mathrm{D}$ band at $1300 \mathrm{~cm}^{-1}$ arises from breathing vibration of carbon rings, while the $G$ band at $1600 \mathrm{~cm}^{-1}$ results from carbon chains vibrations proof the $s p^{2}$ turbostratic microstructure. The additional band can be assigned to $\mathrm{Na}_{2} \mathrm{CO}_{3}$ impurities. The $\mathrm{G}^{\prime}$ band is an overtone, where two phonons are involved. It scales with the numbers of layer in a graphene stack. The $G^{\prime}$ bands are very broad, which indicates a low stacking of the carbon layers. The intensity ratios of the D and $G$ Raman band (Fig. 13f) show no clear trend, which indicates the high structural disorder of the carbon. 

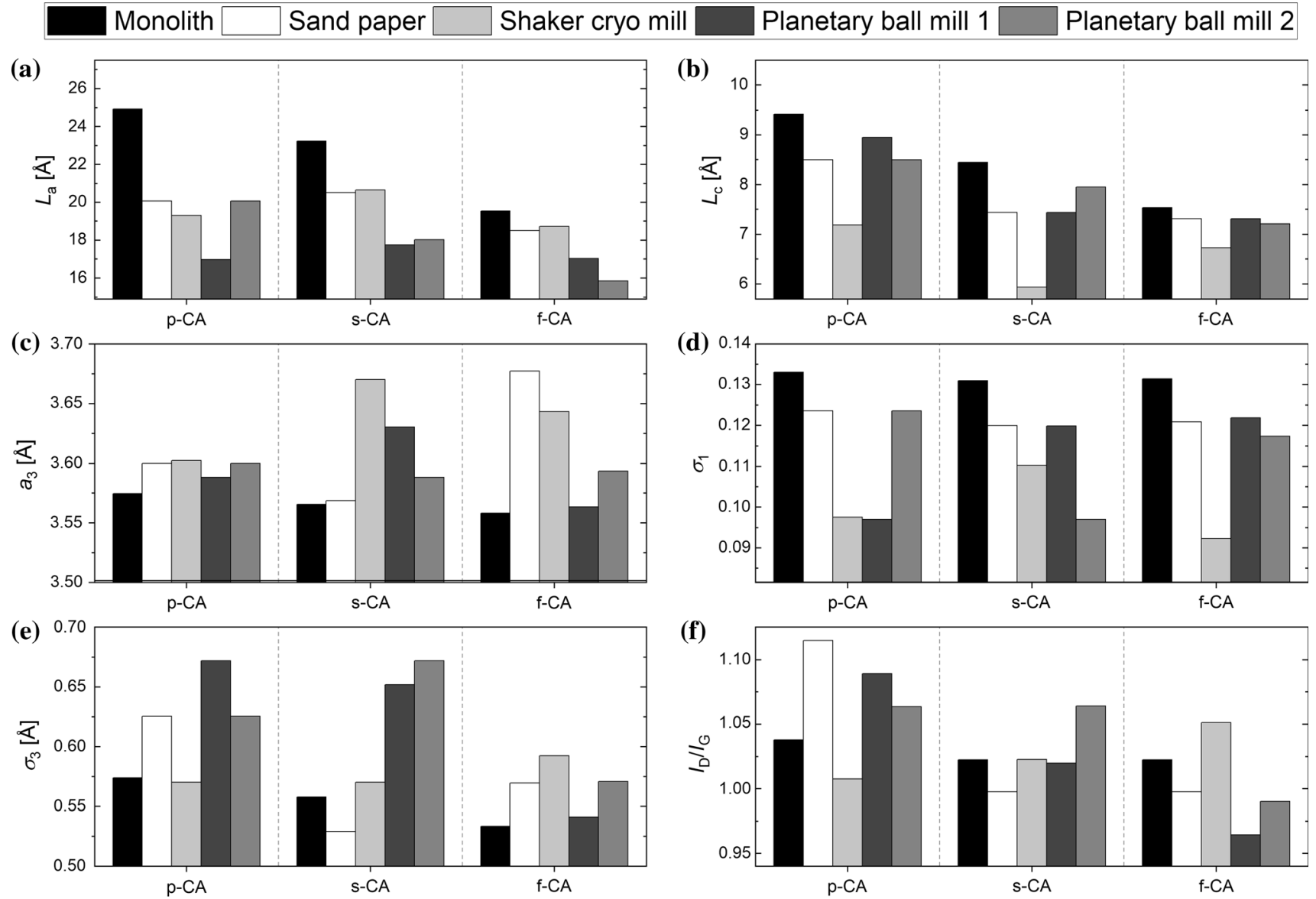

Figure 13 a-e: Microstructural parameter obtained by fitting the WAXS data, with $L_{a}$ graphene layer size, $L_{c}$ the stack size, $a_{3}$ the layer distance and disorder parameter describing $\sigma_{1}$ the disorder

\section{Stiff carbon aerogel}

Generally, the structure of stiff carbon aerogels (sCA) underwent the lowest modification. Nevertheless, the microstructural parameters obtained by fitting of WAXS data show slight changes in the structure. All of investigated pulverization methods are suitable for this kind of aerogels. In order to achieve homogeneous particle size of powder granules further experiments have to be done. Since, shaker cryo-milling and planetary ball milling lead to similar powder properties, the usage of ball mill seems to be more preferred. The procedure of this method is simpler and faster.

within the layers and $\sigma_{3}$ between the layers, $\mathbf{f}$ : the intensity ratio of the $\mathrm{D}$ and $\mathrm{G}$ Raman bands.

\section{Ductile carbon aerogel}

Surprisingly, the most modifications in the structure of ductile p-CA were generated during low-energy grinding and high-energy long milling time in the ball mill (ball mill 2). In both cases, frictional forces produce the greatest deformation of the initial material with cracks appearing due to the mechanical effect of the mill balls and sand particles on the sandpaper. Thus, ductile aerogels show higher sensitivity to frictional forces than to impacts in a shaker mill. Significant changes in pore size distribution are of high importance. It could be shown that high-energy impact causes reduction in micropores and 
Figure 14 Raman spectra of monolithic and pulverized carbon aerogels.
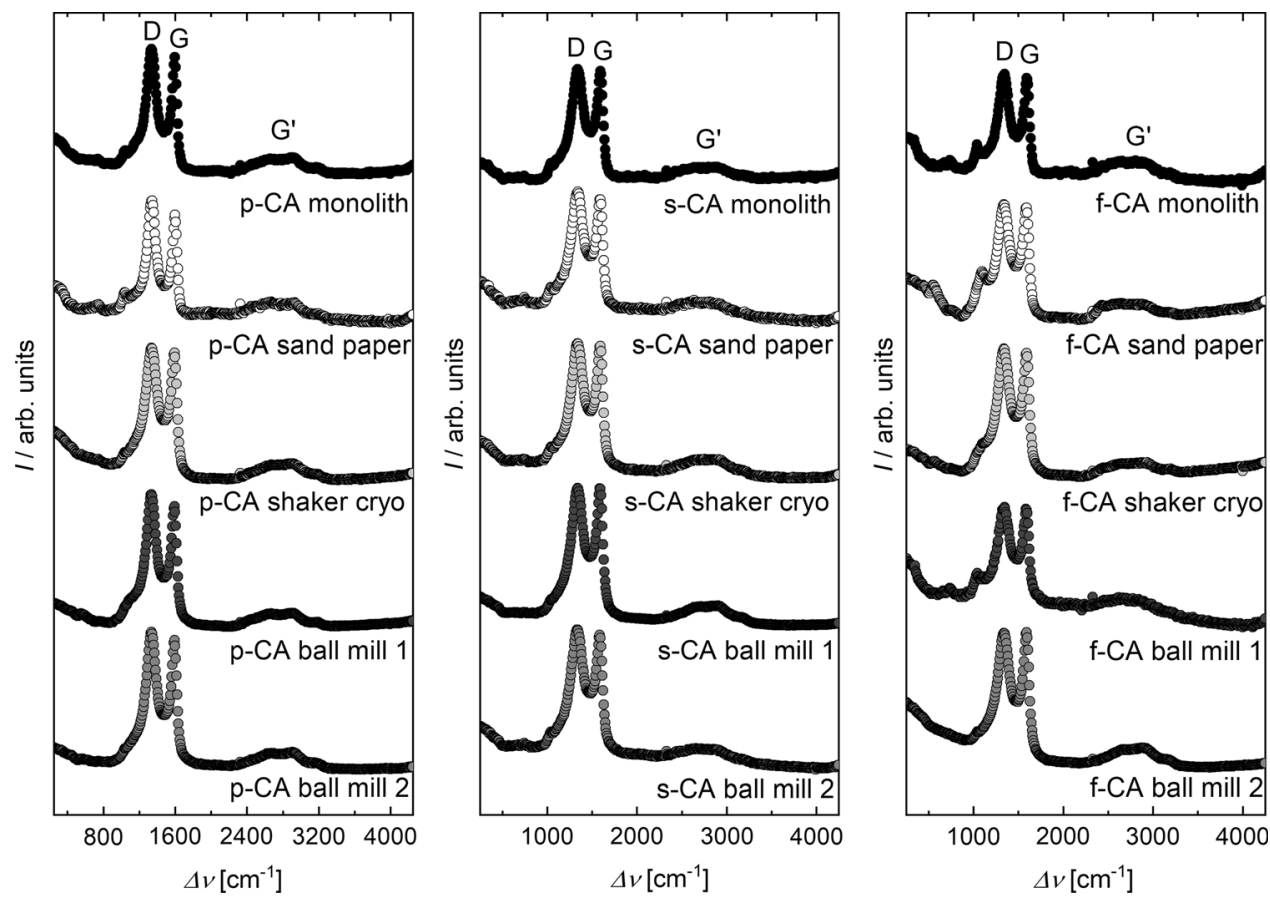

formation of mesopores. Summing up, the methods studied in present work are not suitable for ductile aerogels. Plastic deformations of microstructure during pulverization diversify properties of aerogels.

\section{Flexible carbon aerogel}

Due to poor mechanical resistance of soft $\mathrm{f}-\mathrm{CA}$, the most changes after pulverization were observed in its microstructure. All of the used methods caused modifications: major increase in surface area and micropore volume, and generating of additional meso- and macropores. On that account we conclude, it is challenging to pulverize soft aerogels without affecting their microstructure.

The changes in the structure after pulverization show that not only mechanical properties of aerogels but also their initial microstructures play an important role. The most changes of microporous aerogels (s-CA and f-CA) occurred in micropore region; new mesopores were generated. The structure of mesoporous p-CA was mostly changed in meso- and macropore field. Presumably, mesoporous, ductile aerogels are very sensitive to the frictional forces, which changed the structure of p-CA drastically.

The results show that pulverization strongly influences the morphology of carbon aerogels. Milling in a planetary ball mill, which is the most widely used technique, causes slight decrease in the size of graphene layers and influences the stack size. The cryo-milling technique not only influences the height of the graphene layer stack, but also the distance between graphene layers. These parameters could in turn affect the properties of aerogels such as surface area, electrical conductivity, and pore volume. For the application as electrode material, the modification in the microstructure during pulverization is crucial in order to achieve high-performance energy storage devices. For foundry applications, the pore size distribution is of a high importance. Aerogel powders with modified structure may negatively affect the surface morphology of founded parts. It should be pointed out that all of the investigated methods influence the final structure. For applications where the structure needs to be preserved, alternative methods should be developed for aerogels and other high porous, sensitive materials.

\section{Conclusions}

In the present work, the effect of pulverization methods with different modes of operation on carbon aerogel microstructures was studied. On the one hand, under the same conditions and milling methods, the effect of pulverization strongly depends on 
the nature of the samples. Thus, different changes in stiff, ductile, and flexible aerogels could be shown. On the other hand, the effect of milling and grinding is directly related to the energy used. The results show ductile and flexible aerogels are sensitive against friction. Thus, as the graphene layer distance increased during pulverization, the structure became less compact compared to the monolithic aerogels. Significant changes in the structure lead to an overall increase in the surface area and the pore volume of aerogels after pulverization.

\section{Acknowledgements}

Open Access funding provided by Projekt DEAL. The authors would like to thank Dr Klemens Kelm and Frederic Kreps for discussions on TEM images. We thank Brigitta Sievert and Norbert Wagner for support in shaker cryo-milling, Benjamin Ignatzi for support in milling process, and Rebekka Probst for SEM images.

\section{Authors Contribution}

The conceptualization, methodology and writingoriginal draft preparation were done by MS, JS, and $\mathrm{FB}$, writing - review and editing were done by $\mathrm{CH}$, $\mathrm{BM}$, and $\mathrm{BS}$.

\section{Funding}

Financial support is provided by the German Research Foundation (DFG) via the GRK (Research Training Group) 2204 "Substitute Materials for sustainable Energy Technologies." We would like to acknowledge the Center for Materials Research
(LaMa) at Justus Liebig University Giessen for the support of this project.

\section{Compliance with ethical standards}

Conflict of interest The authors declare no conflict of interest.

Open Access This article is licensed under a Creative Commons Attribution 4.0 International License, which permits use, sharing, adaptation, distribution and reproduction in any medium or format, as long as you give appropriate credit to the original author(s) and the source, provide a link to the Creative Commons licence, and indicate if changes were made. The images or other third party material in this article are included in the article's Creative Commons licence, unless indicated otherwise in a credit line to the material. If material is not included in the article's Creative Commons licence and your intended use is not permitted by statutory regulation or exceeds the permitted use, you will need to obtain permission directly from the copyright holder. To view a copy of this licence, visit http://creativecommons.org/licen ses/by/4.0/.

\section{Appendix A}

Here, we present the microstructures of monolithic, grinded, and milled samples of flexible carbon aerogel. Against our expectation, no visible differences could be observed on SEM images (See Fig. 15).

TG-MS measurements were conducted to investigate the oxidation resistance of the carbon monoliths. The weight loss is contributed to carbon containing groups (See Fig. 16 and Table 4). 
Figure 15 SEM images of microstructure of flexible carbon aerogel (f-CA).

Astonishingly, no visible modification of network could be observed: a original structure of monolithic sample, b grinded sample shows similar particle and pore sizes, c The structure after milling in shaker cryo-mill seems to be not changed; $\mathbf{d}$ powder after milling in planetary ball mill (ball mill 1) and e after prolonged time (ball mill 2) show no noticeable differences.

Figure 16 TG-MS measurements of the monolithic carbons. The weight loss (top) and the corresponding loss of carbon containing groups (middle/ bottom).
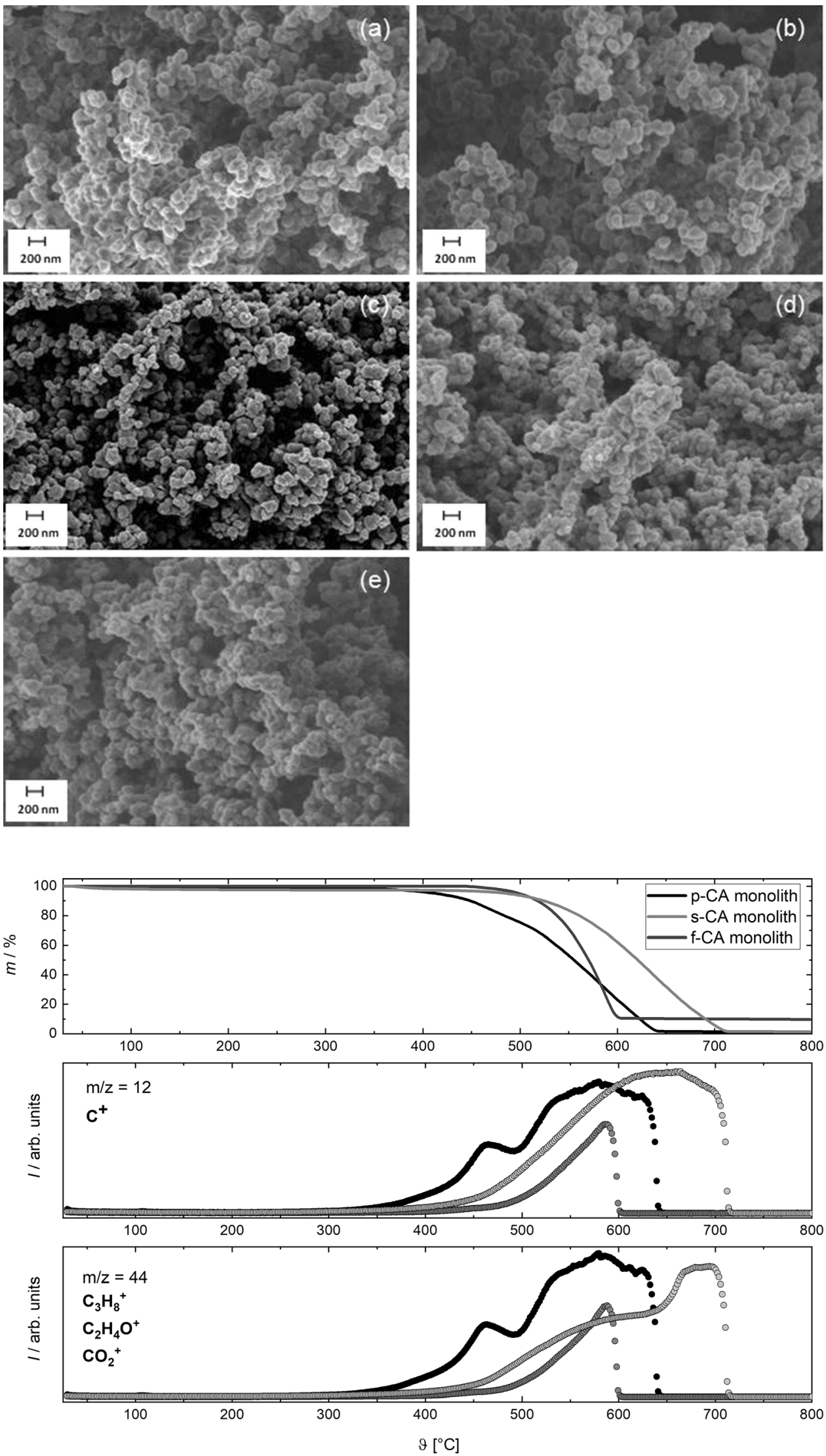
Table 4 Carbon content determined by TG-MS

\begin{tabular}{ll}
\hline Type of aerogel & C content (\%) \\
\hline p-CA & 96 \\
s-CA & 96 \\
f-CA & 89 \\
\hline
\end{tabular}

\section{References}

[1] Pekala RW (1989) Organic aerogels from the polycondensation of resorcinol with formaldehyde. J Mater Sci 24:3221-3227. https://doi.org/10.1007/bf01139044

[2] Pekala RW (1992) Melamine-formaldehyde aerogels. USA Patent US5081163 A

[3] Pekala RW (1998) Organic carbon aerogels from the sol-gel polymerization of phenolic-furfural mixtures. USA Patent US5744510 A

[4] Shen J, Guan DY (2011) Preparation and application of carbon aerogels. In: Aegerter AM, Leventis N, Koebel MM (eds) Aerogels handbook. Springer, New York, pp 813-831. https://doi.org/10.1007/978-1-4419-7589-8 36

[5] Park D-W, Cañas NA, Schwan M, Milow B, Ratke L, Friedrich KA (2016) A dual mesopore C-aerogel electrode for a high energy density supercapacitor. Curr Appl Phys 16(6):658-664. https://doi.org/10.1016/j.cap.2016.03.021

[6] Balakumar K, Kalaiselvi N (2015) High sulfur loaded carbon aerogel cathode for lithium-sulfur batteries. RSC Adv 5(43):34008-34018. https://doi.org/10.1039/C5RA01436K

[7] Guilminot E, Fischer F, Chatenet M, Rigacci A, BerthonFabry S, Achard P, Chainet E (2007) Use of cellulose-based carbon aerogels as catalyst support for PEM fuel cell electrodes: electrochemical characterization. J Power Sources 166(1):104-111. https://doi.org/10.1016/j.jpowsour.2006.12. 084

[8] Ratke L, Milow B (2011) Aerogels for foundry applications. In: Aegerter MA, Leventis N, Koebel MM (eds) Aerogels handbook. Advances in sol-gel derived materials and technologies. Springer, New York, pp 763-788. https://doi.org/ 10.1007/978-1-4419-7589-8_34

[9] Sabri F, Marchetta J, Smith KM (2013) Thermal conductivity studies of a polyurea cross-linked silica aerogel-RTV 655 compound for cryogenic propellant tank applications in space. Acta Astronaut 91:173-179. https://doi.org/10.1016/ j.actaastro.2013.06.001

[10] Zhou J, Liu BH, Li ZP (2013) Nanostructure optimization of $\mathrm{LiFePO}_{4} /$ carbon aerogel composites for performance enhancement. Solid State Ion 244:23-29. https://doi.org/10. 1016/j.ssi.2013.05.003
[11] Immohr S, Felderhoff M, Weidenthaler C, Schüth F (2013) An orders-of-magnitude increase in the rate of the solidcatalyzed $\mathrm{CO}$ oxidation by in situ ball milling. Angew Chem 125(48):12920-12923. https://doi.org/10.1002/ange. 201305992

[12] Craig SL (2012) A tour of force. Nature 487:176. https://doi. org/10.1038/487176a

[13] Bakierska M, Chojnacka A, Świętosławski M, Natkański P, Gajewska M, Rutkowska M, Molenda M (2017) Multifunctional carbon aerogels derived by sol-gel process of natural polysaccharides of different botanical origin. Materials $10(11): 1336$

[14] Bian Q, Chen S, Kim B-T, Leventis N, Lu H, Chang Z, Lei S (2011) Micromachining of polyurea aerogel using femtosecond laser pulses. J Non-Cryst Solids 357(1):186-193. h ttps://doi.org/10.1016/j.jnoncrysol.2010.09.037

[15] Zanini M, Lavoratti A, Lazzari LK, Galiotto D, Baldasso C, Zattera AJ (2018) Obtaining hydrophobic aerogels of unbleached cellulose nanofibers of the species Eucalyptus sp. and Pinus elliottii. J Nanomater 2018:11. https://doi.org/ 10.1155/2018/4646197

[16] Schwan M, Naikade M, Raabe D, Ratke L (2015) From hard to rubber-like: mechanical properties of resorcinolformaldehyde aerogels. J Mater Sci 50(16):5482-5493. h ttps://doi.org/10.1007/s10853-015-9094-x

[17] Rege A, Schwan M, Chernova L, Hillgärtner M, Itskov M, Milow B (2020) Microstructural and mechanical characterization of carbon aerogels: an in situ and digital image correlation-based study. J Non-Cryst Solids 529:119568. h ttps://doi.org/10.1016/j.jnoncrysol.2019.119568

[18] Haynes WM (1974) CRC handbook of chemistry and physics. CRC Press, Boca Raton

[19] Loeh MO, Badaczewski F, Faber K, Hintner S, Bertino MF, Mueller P, Metz J, Smarsly BM (2016) Analysis of thermally induced changes in the structure of coal tar pitches by an advanced evaluation method of X-ray scattering data. Carbon 109:823-835. https://doi.org/10.1016/j.carbon.2016.08. 031

[20] Faber K, Badaczewski F, Oschatz M, Mondin G, Nickel W, Kaskel S, Smarsly BM (2014) In-depth investigation of the carbon microstructure of silicon carbide-derived carbons by wide-angle X-ray scattering. J Phys Chem C 118(29):15705-15715. https://doi.org/10.1021/jp502832x

[21] Faber K, Badaczewski F, Ruland W, Smarsly BM (2014) Investigation of the microstructure of disordered, non-graphitic carbons by an advanced analysis method for wide-angle X-ray scattering. Z Anorg Allg Chem 640(15):3107-3117. h ttps://doi.org/10.1002/zaac.201400210 
[22] Ruland W, Smarsly B (2002) X-ray scattering of non-graphitic carbon: an improved method of evaluation. J Appl Crystallogr 35(5):624-633. https://doi.org/10.1107/S0021889802011007

[23] Pfaff T, Badaczewski FM, Loeh MO, Franz A, Hoffmann J-U, Reehuis M, Zeier WG, Smarsly BM (2019) Comparative microstructural analysis of nongraphitic carbons by wide-angle X-ray and neutron scattering. J Phys Chem C 123(33):20532-20546. https://doi.org/10.1021/acs.jpcc.9b 03590

[24] Loeh MO, Badaczewski F, von der Lehr M, Ellinghaus R, Dobrotka S, Metz J, Smarsly BM (2018) Hard-templating of carbon using porous $\mathrm{SiO}_{2}$ monoliths revisited-quantitative impact of spatial confinement on the microstructure evolution. Carbon 129:552-563. https://doi.org/10.1016/j.ca rbon.2017.12.044

[25] Badaczewski F, Loeh MO, Pfaff T, Dobrotka S, Wallacher D, Clemens D, Metz J, Smarsly BM (2019) Peering into the structural evolution of glass-like carbons derived from phenolic resin by combining small-angle neutron scattering with an advanced evaluation method for wide-angle X-ray scattering. Carbon 141:169-181. https://doi.org/10.1016/j.carbo n.2018.09.025

Publisher's Note Springer Nature remains neutral with regard to jurisdictional claims in published maps and institutional affiliations. 